\title{
A Floating Quadrat
}

\author{
G.W. TANNER AND M.E. DRUMMOND
}

\section{Abstract}

A clipping quadrat of PVC pipe was constructed to sample emergent phytomass in freshwater marshes. This apparatus is light and durable, and most importantly, has the ability to float. It can be constructed to meet most commonly used quadrat sizes with the ability to be assembled and dismantled in the field for ease of transportation. Terrestrial applications for this type of quadrat also are possible.

In Florida and throughout much of the Southeastern coastal plain, freshwater marshes provide an excellent source of cattle forage. In many of the riverine, or flow through, and pond-type marshes, water levels fluctuate seasonally due to such factors as periodic drought or heavy rainfall and manipulation of stage levels for flood control and lake drawdowns. Availability of usable forage, therefore, varies with water depth.

Cattle wade into marshes to graze emergent vegetation. To measure grazing capacity of a marsh, the emergent biomass must be sampled. Quadrat frames typically used in clipping procedures are metal and have a tendency to sink when used in aquatic environments. Wooden frames will float, but become waterlogged, heavy and subject to rapid deterioration. Therefore, we made a 1 $\mathrm{m}^{2}$ quadrat of standard $12.7 \mathrm{~mm}$ ( 0.5 inch) PVC pipe (Fig. 1).

The quadrat consisted of four pieces of pipe cut to the desired length and four $90^{\circ}$ elbows. This quadrat is quickly assembled and dismantled in the field. However, it is advised to permanently cement the $90^{\circ}$ elbows on alternate corners to avoid their loss. The quadrat can be subdivided into subquadrats by attaching wire or a thin, elastic shock cord through holes drilled at desired intervals in the pipe. Although the frame will continue to float when full of water, any water entering the frame can be easily discarded by separating a corner and tilting the frame. The quadrat frame is easily worked through the vegetation to the water surface. If the

Authors are assistant professor and graduate assistant, respectively, Department of Wildlife and Range Sciences, University of Florida, Gainesville 32611.

This article is Florida Agricultural Experiment Station Journal Series Art. \#5816.

Manuscript accepted September 19, 1984.

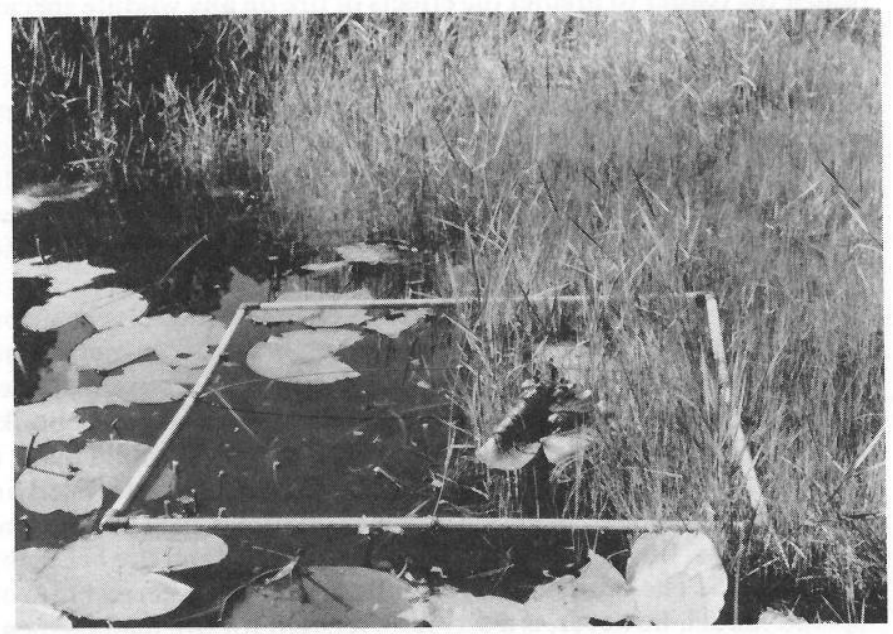

Fig. 1. Clipping emergent vegetation at water level within a $1 \mathrm{~m}^{2}$ floating quadrat.

emergent vegetation is sparse, two metal rods can be inserted into the substrate on diagonal corners to keep the frame stationary while clipping.

According to 1984 prices, thin-walled PVC pipe costs approximately $\$ 0.38 / \mathrm{m}$, while Schedule 40 pipe costs $\$ 0.59 / \mathrm{m} ; 90^{\circ}$ elbows cost $\$ 0.32$ each. At these prices a $1 \mathrm{~m}^{2}$ square frame would cost $\$ 2.80$ for thin-walled PVC or $\$ 3.64$ for the more sturdy pipe.

Since the quadrat is easily dismantled, it becomes a portable, liveweight and rugged frame for field use. We believe this frame design also could be used for terrestrial plant sampling. The rigid $90^{\circ}$ elbows will force and maintain the frame into a square configuration without additional adjustment. In-line couplings can be used to expand the quadrat size up to a $5 \mathrm{~m} \times 5 \mathrm{~m}$ quadrat without excessive addition of weight or bulk - a necessary requirement for field application. 